\title{
"JAFE \\ Heat transfer assessment of multi-tier chilling pipes for root zone cooling system under crop protection structure in the tropics
}

Ahmad Syafik Suraidi Sulaiman a*, Mohd Ashraf Zainol Abidin b, Desa Ahmad c

aProgram Pertanian Tepat (ER3), Pusat Penyelidikan Kejuruteraan, Ibu Pejabat MARDI, Persiaran MARDI-UPM, 43400 Serdang, Selangor Malaysia. ${ }^{b}$ Faculty of Plantation and Agrotechnology, Universiti Teknologi MARA Perlis Branch, Arau Campus, 02600 Arau, Perlis, Malaysia.

cDepartment of Biological and Agricultural Engineering, Faculty of Engineering, Universiti Putra Malaysia, 43400 UPM Serdang, Selangor Malaysia.

\section{ARTICLE HISTORY}

Abstract

Received: 24 December 2020

Received in revised form: 26 August 2021

Accepted: 30 August 2021

Available Online: 16 September 2021

\section{Keywords}

Root zone cooling

Crop protection structure

Heat transfer
Root zone cooling technique has become an alternative cultivation method for temperate crops production in the tropics instead of cooling the aerial environment of the greenhouse. In this experiment, the root zone cooling system was incorporated with a multi-tier crop cultivation structure. This structure consisted of five tiers arranged in an A-shape design and was placed under an open rain shelter, thus, left it to undergo fluctuating environment temperature. There were five pillow polybags inserted with cocopeat and were placed on the structure. Each pillow polybag consisted of a single pipe that was buried inside the growth media located near the root zone area. This pipe that was connected to the chilled system acted as a cooling agent in controlling the growth media temperature. The objective of the study was to evaluate the Root Zone Cooling (RZC) system performance in distributing and controlling water-dissolved nutrient temperatures to meet crop-root requirement needs. From the experiment conducted, it was found that there was no significant difference between root zone temperature at different levels and lengths on multi-tier structure. The chilling pipes was able to distribute the temperatures to meet crop-root requirement needs along the multi-tier structure.

\subsection{Introduction}

Multi-tier cultivation is a system used to grow plants vertically. This cultivation technique is rapidly used in intensive farming and urban agriculture due to its reliability and suitability (Bartholomew, 2005). According to Mohd Ridzuan (2011), apart from increasing the number of crop planting per cultivation area, crop management such as planting, breeding, pest and disease control, weeding, irrigation system, and harvesting become easier by using this technique. Mohd Ashraf (2013) added that this system can enhance crop production and growth needs. However, this technique is more exposed than non-staked plants, makes the growth media and crop dry out quickly (Derek, 2011), thus, may increase the growth media temperature.

Instead of cooling the aerial environment, the root zone cooling system has become an alternative method in the control environment technique for crop production. This method shows significant results in increasing plant growth, improving crop productivity and reducing energy consumption. Gosselin and Trudel (1984) stated that crop productivity can be maintained under fluctuating ambient temperature when root zone temperature was controlled. The effect of root zone temperature is greater on crops root growth especially in the early stage of crop development (Mohammud et al., 2012). Mohammud et al. (2012) stated that when Lactuca satica are cultivated using the root zone cooling method, the crops are growing rapidly and quickly compared to the crop that harvested using standard practice cultivation at the early week of crop development. However, extreme root zone temperature manipulation can cause excessive vegetative growth, flower abscission and poor fruit set. Thus, it is important to consider the crop requirements before planning for cooling technique (Mat Sharif, 2006).
Growth media play a major role in transferring the nutrient for the crop propagation and holding the root to avoid the crop falling down. Cocopeat is one of the common growth media used in soilless cultivation techniques. It is considered a good medium for crop cultivation because it consists of acceptable $\mathrm{pH}$, electrical conductivity, and other chemical properties (Yahya, 2009). According to Abou-Hadid and E-Behairy (1999), a soilless cultivation technique using cocopeat has been recognized to have high water holding capacity, thus, becomes more important in the arid and semi-arid region of the world.

In this experiment, the root zone cooling system was incorporated with a multi-tier cultivation structure. This structure consisted of five tiers arranged in an A-shape design and was placed under an open rain shelter, thus, left it to undergo fluctuating environment temperature. There are five pillow polybags inserted with cocopeat and were placed on the structure. Each pillow polybag consisted of a single pipe that was buried inside the growth media located near the root zone area. Furthermore, environment and soil parameters such as environment temperature $\left({ }^{\circ} \mathrm{C}\right)$, relative humidity $(\%)$, solar radiation (watt $\left./ \mathrm{m}^{2}\right)$, wind speed $(\mathrm{m} / \mathrm{s})$, and soil moisture content (\%) were also measured to determine their regressions on growth media temperatures $\left({ }^{\circ} \mathrm{C}\right)$. The objective of the study was to evaluate the Root Zone Cooling (RZC) system performance in distributing and controlling water-dissolved nutrient temperatures to meet crop-root requirement needs.

\section{Materials and methods}

The experiments were conducted under an open rain shelter structure located at Malaysian Agricultural Research and Development Institute (MARDI) in Serdang, Selangor, Malaysia with a latitude of $2^{0} 59^{\prime} \mathrm{N}$, longitude $101^{0} 42^{\prime} \mathrm{E}$ and $37.8 \mathrm{~m}$ above 
the sea level. A single multi-tier structure was used in this experiment (Figure 1). The structure consisted of five tiers arranged in an A-shape design, thus, makes the structure having three different height levels. Level 1 was $0.5 \mathrm{~m}$ from the ground while level 2 and level 3 were $1.0 \mathrm{~m}$ and $1.5 \mathrm{~m}$ respectively from the ground. A 10 meters pillow polybag filled with cocopeat as a growth media was placed on each of the tiers. Then, a single pipe was also buried inside each pillow polybag. This pipe that was connected to the chilled system acted as a cooling agent in controlling the growth media temperature.

Each of the inlet and outlet pipes was inserted with a temperature sensor that was connected to the Watchdog data logger (Figure 2). The temperature of the water inside the pipe was recorded automatically every 30 minutes.

Two 5TE Decagon sensors that have the capacity to measure the soil temperature and moisture content were buried inside the growth media at 3 meters from each end of the pillow polybag making the total number of sensors used in this experiment as 10 units (Figure $3 \mathrm{~A}$ ). Each point was labelled as T1P1, T1P2, T2P1, T2P2, T3P1, T3P2, T4P1, T4P2, T5P1, and T5P2. The entire sensors were connected to EM50 Data Collection System and both data were recorded automatically every 30 minutes (Figure 3B).

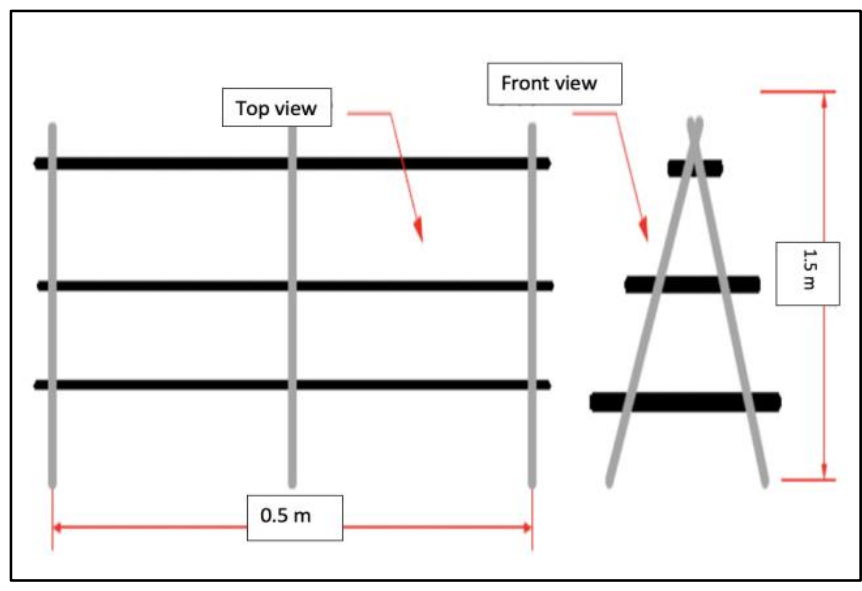

Figure 1. The layout of multi-tier structure

The Watchdog weather station was also used to record environment parameters such as environment temperature $\left({ }^{\circ} \mathrm{C}\right)$, relative humidity $(\%)$, solar radiation (watt $\left./ \mathrm{m}^{2}\right)$ and wind speed (m/s) every 30 minutes automatically (Figure 4).

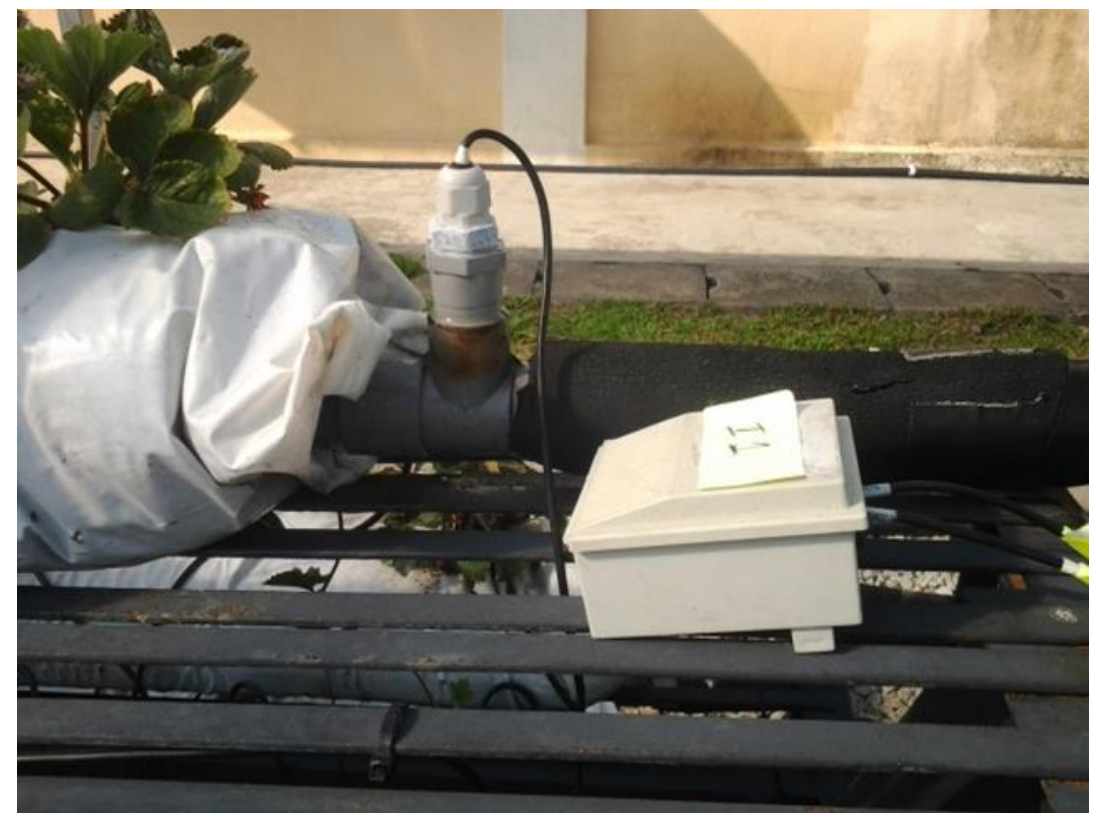

Figure 2. Temperature sensor plug into the pipe and connected to the data logger
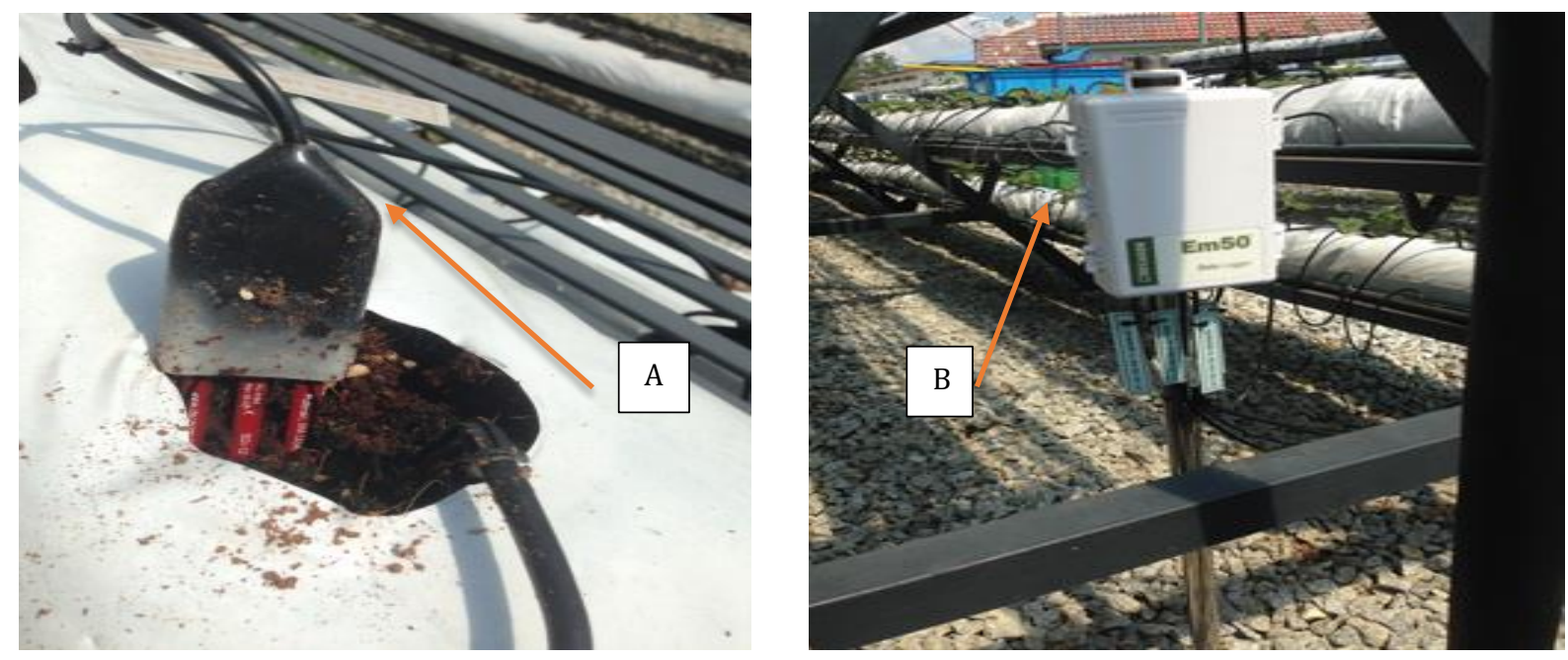

Figure 3. Soil temperature (A) and moisture content (B) sensors connected to the data logger 


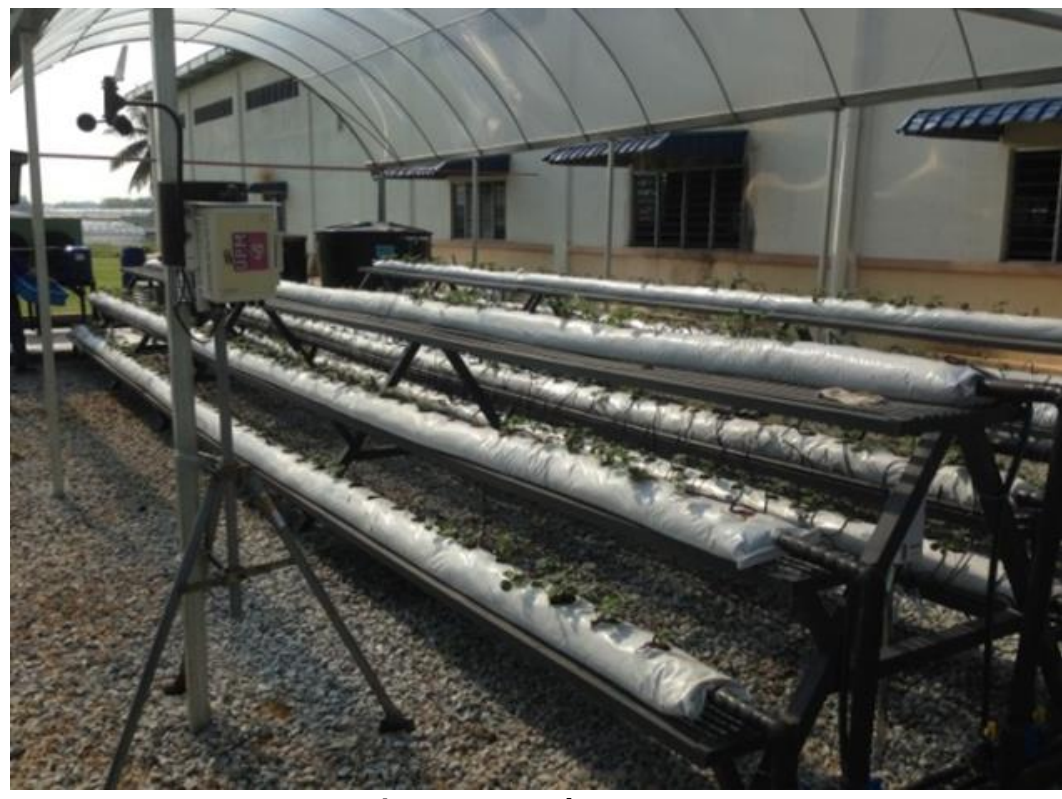

Figure 4. Weather station

The recorded data then were analysed using IBM SPSS Statistics 21 to evaluate the potential of the root zone cooling system in providing the uniform growth media temperature in a multi-tier cultivation technique. The results were compared with previous experiments conducted by Mohd Ashraf (2013) for small scale structure.

\section{Results and discussion}

\subsection{Root zone temperatures at different levels and lengths of multi-tier structure}

Table 1 shows ten different locations in the multi-tier structure where root zone temperatures were being measured. Points T1P1, T1P2, T5P1, and T5P2 were located at $0.5 \mathrm{~m}$ from the ground. Points T2P1, T2P2, T4P1, and T4P2 were located at $1.0 \mathrm{~m}$ from the ground while points T3P1 and T3P2 were located at the third level $1.5 \mathrm{~m}$ from the ground.

There were two different lengths where root zone temperatures were being measured. Points T1P1, T2P1, T3P1, T4P1 and T5P1 were measured $3.0 \mathrm{~m}$ from the beginning of the multi-tier structure while T1P2, T2P2, T3P2, T4P2 and T5P2 were measured $7.0 \mathrm{~m}$ from the beginning of the same multi-tier structure.

Based on the above results, point T1P1 had the lowest maximum, minimum, range and mean temperatures which were $29.8^{\circ} \mathrm{C}, 9.9^{\circ} \mathrm{C}, 19.9^{\circ} \mathrm{C}$, and $23.8^{\circ} \mathrm{C}$ respectively. In contrast, a similar position which is point T5P1 had high maximum, minimum, range, and mean temperatures than point T1P1. These results were similar to the results obtained in previous experiments done by Mohd Ashraf (2013) for small scale structure, where, the results are as shown in Table 2. In both experiments, the main pipe that channelled the cold water to the chilled pipes was located close to T1's tier. It shows that the position of the main pipe influences the temperature at multitier structure.

When comparing the root zone temperatures at different levels of multi-tier structure, it shows that different levels do not necessarily influence the root zone temperatures. These have been represented by several comparisons between different points at different levels such as comparisons between points T2P1 and T3P1 and also T2P2 and T3P2. However, the results were in contrast to the results of previous experiments using small scale structure (Table 2).

Most of the results at different lengths of multi-tier structure suggest that there were some increasing trends in root zone temperature along the multi-tier structure. Although some results obtained were consistent with previous experiments, the range of root zone temperatures varies between large scale and small-scale structures. However, more analysis was carried out, as reported in part $B$ to determine the potential of the root zone cooling system in order to provide an acceptable range of root zone temperature in multi-tier structure.

Table 1. Max, min, range, and average root zone temperatures in a large-scale multi-tier structure

\begin{tabular}{lllllll}
\hline \multirow{2}{*}{ Point } & Position & & Max $\left({ }^{\circ} \mathrm{C}\right)$ & Min $\left({ }^{\circ} \mathrm{C}\right)$ & Range $\left({ }^{\circ} \mathrm{C}\right)$ & Mean $\left({ }^{\circ} \mathrm{C}\right)$ \\
\cline { 2 - 5 } & Height $(\mathrm{m})$ & Length $(\mathrm{m})$ & & & \\
\hline T1P1 & 0.5 & 3 & 29.8 & 19.9 & 9.9 & 23.8 \\
T1P2 & 0.5 & 7 & 32.2 & 21.7 & 10.5 & 26.2 \\
T2P1 & 1.0 & 3 & 33.6 & 20.9 & 12.7 & 25.9 \\
T2P2 & 1.0 & 7 & 33.5 & 22.1 & 11.4 & 26.8 \\
T3P1 & 1.5 & 3 & 33.5 & 21.5 & 12 & 26.4 \\
T3P2 & 1.5 & 7 & 32.3 & 20.5 & 11.8 & 25.6 \\
T4P1 & 1.0 & 3 & 31.7 & 21 & 10.7 & 25.3 \\
T4P2 & 1.0 & 7 & 30.9 & 20.6 & 10.3 & 25 \\
T5P1 & 0.5 & 3 & 31.7 & 21.5 & 10.2 & 25.5 \\
T5P2 & 0.5 & 7 & 31.4 & 21.5 & 9.9 & 25.5 \\
\hline Average & & & 32.1 & 21.1 & 10.9 & 25.6 \\
\hline
\end{tabular}


Table 2. The maximum ( $\max$ ), minimum ( $\mathrm{min}$ ), range and average root zone temperatures in small scale multi-tier structure

\begin{tabular}{|c|c|c|c|c|c|c|}
\hline \multirow[b]{2}{*}{ Point } & \multicolumn{2}{|l|}{ Position } & \multirow{2}{*}{$\operatorname{Max}\left({ }^{\circ} \mathrm{C}\right)$} & \multirow{2}{*}{$\operatorname{Min}\left({ }^{\circ} \mathrm{C}\right)$} & \multirow{2}{*}{ Range $\left({ }^{\circ} \mathrm{C}\right)$} & \multirow{2}{*}{$\operatorname{Mean}\left({ }^{\circ} \mathrm{C}\right)$} \\
\hline & Height (m) & Length (m) & & & & \\
\hline T1P1 & 0.4 & 1.0 & 22.6 & 19.7 & 2.9 & 21.4 \\
\hline T1P2 & 0.4 & 3.0 & 25.5 & 21.2 & 4.3 & 23.3 \\
\hline T2P1 & 0.8 & 1.0 & 24.2 & 20.4 & 3.8 & 22.3 \\
\hline T2P2 & 0.8 & 3.0 & 27.0 & 21.7 & 5.3 & 24.1 \\
\hline Т3Р1 & 1.2 & 1.0 & 31.1 & 22.7 & 8.4 & 26.3 \\
\hline T3P2 & 1.2 & 3.0 & 32.2 & 23.6 & 8.6 & 27.3 \\
\hline T4P1 & 0.8 & 1.0 & 29.6 & 23.1 & 6.5 & 26.1 \\
\hline T4P2 & 0.8 & 3.0 & 29.6 & 23.0 & 6.6 & 25.9 \\
\hline T5P1 & 0.4 & 1.0 & 29.0 & 21.5 & 7.5 & 24.6 \\
\hline T5P2 & 0.4 & 3.0 & 29.0 & 21.8 & 7.2 & 24.9 \\
\hline Average & & & 28.0 & 21.9 & 6.1 & 24.6 \\
\hline
\end{tabular}

Table 3. Multiple Comparison using Tukey HSD Test

\begin{tabular}{|c|c|c|c|c|c|c|}
\hline \multicolumn{7}{|c|}{ Multiple Comparisons Dependent Variable: Temperature. Tukey HSD } \\
\hline \multirow{2}{*}{ (I) Level } & \multirow{2}{*}{ (J) Level } & \multirow{2}{*}{ Mean Difference (I-J) } & \multirow{2}{*}{ Standard Error } & \multirow[b]{2}{*}{ Significant } & \multicolumn{2}{|c|}{ 95\% Confidence Interval } \\
\hline & & & & & Lower Bound & Lower Bound \\
\hline \multirow{2}{*}{1} & 2 & -0.3875 & 0.7386 & 0.859 & -2.1372 & 1.3622 \\
\hline & 3 & -0.7062 & 0.7386 & 0.606 & -2.4559 & 1.0434 \\
\hline \multirow{2}{*}{2} & 1 & 0.3875 & 0.7386 & 0.859 & -1.3622 & 2.1372 \\
\hline & 3 & -0.3187 & 0.7386 & 0.903 & -2.0684 & 1.4309 \\
\hline \multirow{2}{*}{3} & 1 & 0.7062 & 0.7386 & 0.606 & -1.0434 & 2.4559 \\
\hline & 2 & 0.3187 & 0.7386 & 0.903 & -1.4309 & 2.0684 \\
\hline
\end{tabular}

* The mean difference is significant at the 0.05 level

\subsection{Analysis of significant difference for growth media temperature}

Further analysis was carried out to determine the potential of the root zone cooling system in providing an acceptable range of root zone temperature in all points at multi-tier structure.

\subsubsection{Growth media temperature at different levels of multi- tier structure}

The Multiple Comparisons using the Tukey HSD test (table 3 ) was conducted to determine the significant difference in root zone temperature. The result clearly shows that the null hypothesis was accepted, and the alternative hypothesis is rejected. The null hypothesis states that no difference in root zone cooling system at different levels of multi-tier structure. It proves that the three-layer design of a multi-tier structure was accepted because the root zone temperature was still within the acceptable range. However, based on the mean of growth media temperatures at different heights of multi-tier structure, there are small increasing values (Figure 5).

\subsubsection{Growth media temperatures at different lengths in multi-tier structure}

Based on the analysis, the Levene's test has a probability greater than 0.5 , thus, indicates that the population variances are relatively equal. In the Independent Samples Test as shown in Table 4, the two-tail significance for root zone temperature indicates that $p>0.05$ and, therefore, is not significant. Thus, the null hypothesis was accepted and the alternative hypothesis was rejected. It shows that the two-point groups must come from the same population because no significant differences exist at $t$ $(94)=-0.53, p>0.05$. However, from the graph in Figure 5, there are a small increasing trend from point 1 to point 2 .

Despite having the increasing trends along the multi-tier structure, the analysis shows that the range of root zone temperature is still in the acceptable range. Thus, the null hypothesis that states no difference of root zone temperature along the multi-tier was accepted and proves that the length of the multi-tier structure was reasonable.

Table 4. Independent Samples Test

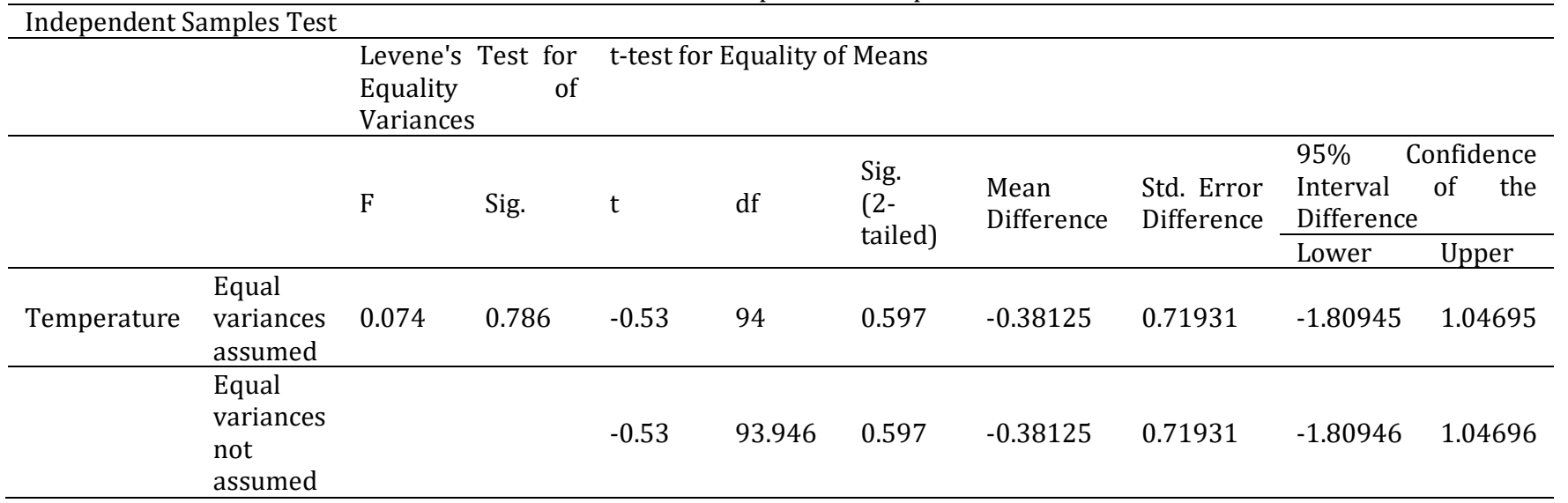




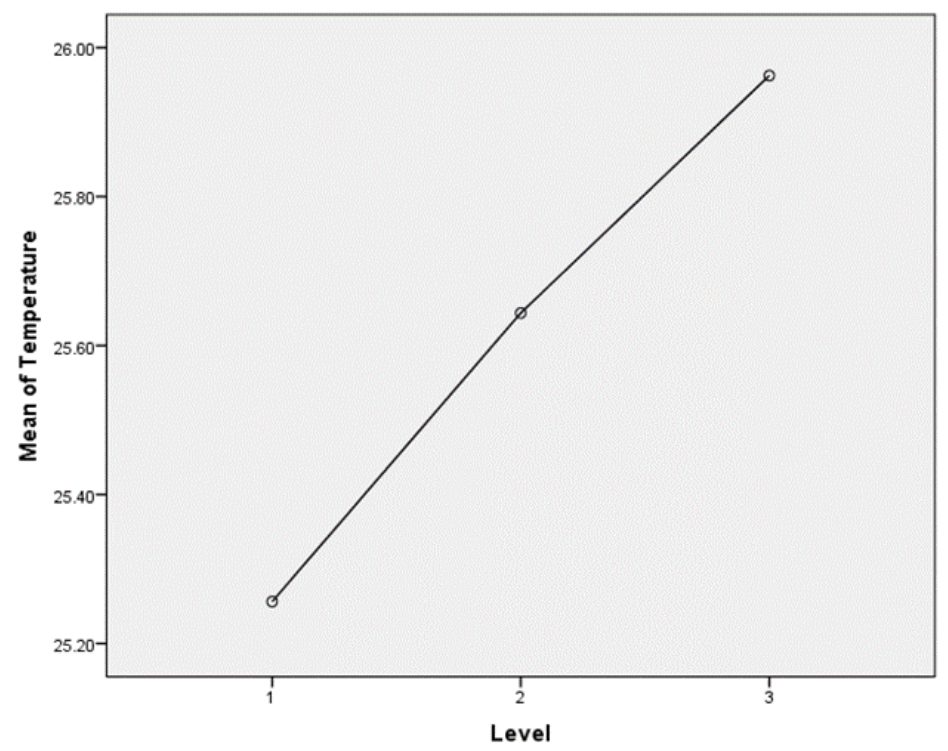

Figure 5. Mean of growth media temperatures at different heights of multi-tier structure

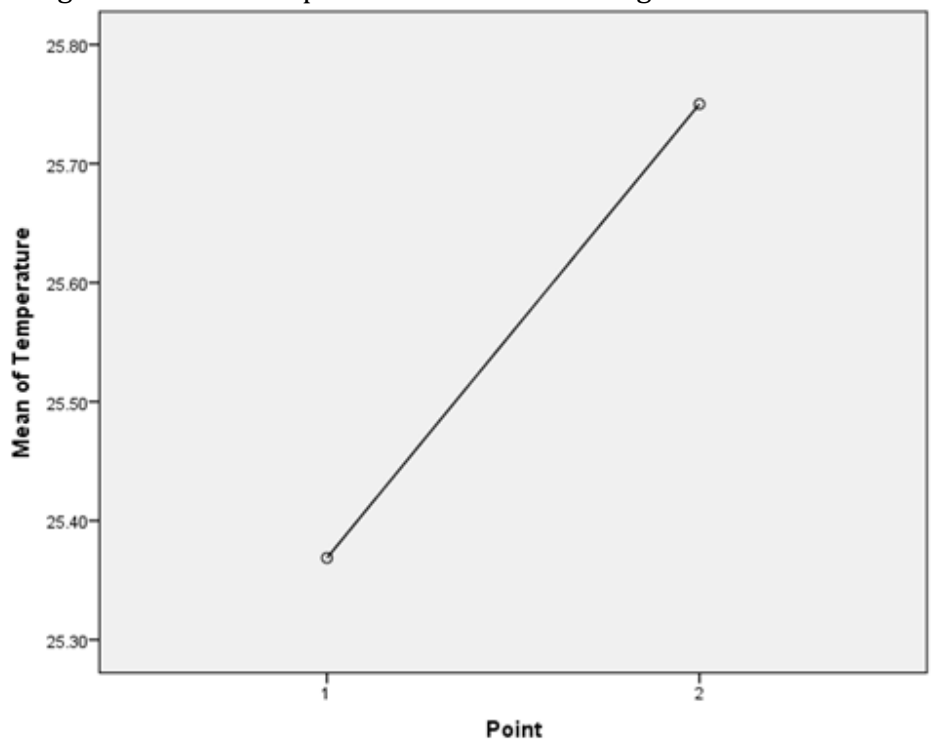

Figure 6. Mean of growth media temperatures at different lengths of multi-tier structure

\subsection{Root Zone Temperatures vs Time}

The root zone temperature at every point versus time is plotted as shown in Figure 7. This graph represents recorded data at every 30 minutes interval per day. All the ten points show a similar pattern either during the increasing or decreasing trends. This similar pattern shows that the chiller system can transfer the heat to the root zone area of the crop uniformly and the usage of cocopeat as growing media also contributes to this pattern. By controlling the temperature of the medium with cold water pipes buried along the root zone area of the plants, the warm temperature will be cooled by the heat exchange process (Wan Fazilah, 2017). Hereafter, interest arises on the effect of RZC on the water retention curve (WRC) and hysteresis for the cocopeat porous medium. The sequence of wetting and drying processes which can be subjected to hysteresis will then influence water content in the medium.

Figure 8 represents average root zone temperatures in large (Experiment) and small (data taken from the previous experiment done by Mohd Ashraf, 2013) multi-tier structure. Both structures show a similar increasing and decreasing pattern of root zone cooling system. However, the small structure had a lower root zone temperature at any time compared to the large structure. Based on the graph, the mean difference between both temperatures is around $14 \%$. This indicates that the longer the structure is equipped with the chilled pipe, the higher the root zone temperature along the pipe. The difference is consistent with the principle of heat loss through forced convection along the pipe. According to Incropera (2007), in this principle, the pressure drops and heat transfer rate when the water flows along the pipe have influence on the pipe length, thus, increasing the temperature.

\section{Temperature vs Time}
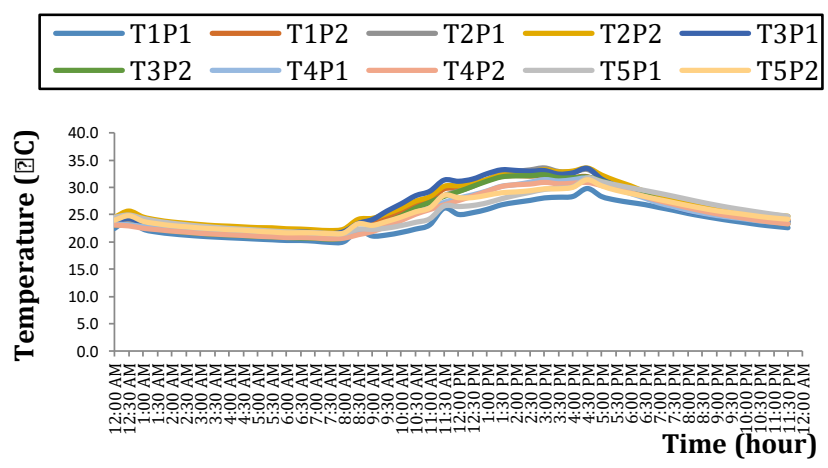

Figure 7. Root zone temperature at every point vs time 


\subsection{Prediction of Root Zone Temperature using Multiple Stepwise Regression}

A multiple stepwise regression was run to predict root zone temperature using Multiple Regression from several factors such as soil moisture content (\%), chilled water temperature $\left({ }^{\circ} \mathrm{C}\right)$, environment temperature $\left({ }^{\circ} \mathrm{C}\right)$, environment relative humidity $(\%)$, solar radiation $\left(\mathrm{w} / \mathrm{m}^{2}\right)$ and wind speed $(\mathrm{m} / \mathrm{s})$ (table 5). The best was chosen and all variables statistically significant in predicting root zone temperature with $\mathrm{p}<0.0005$, $\mathrm{R}^{2}=0.995$. The result shows that all the parameters such as soil moisture content $(\%)$, chilled water temperature $\left({ }^{\circ} \mathrm{C}\right)$, environment temperature $\left({ }^{\circ} \mathrm{C}\right)$, environment relative humidity $(\%)$, solar radiation $\left(\mathrm{w} / \mathrm{m}^{2}\right)$ and wind speed $(\mathrm{m} / \mathrm{s})$ are all effecting the temperatures of the root zone area.

Based on Table 6, the regression model for predicting the root zone temperature is given by the equation, RZT $=-0.005+$ 0.596 (Water Temperature) +0.327 (Environment Temperature) +0.251 (Soil Moisture Content) +0.005 (Solar Radiation) - 0.891 (Wind Speed). From this regression model, several factors that have influenced the root zone temperature could be manipulated to lower the root zone temperature.

\section{Temperature vs Time}
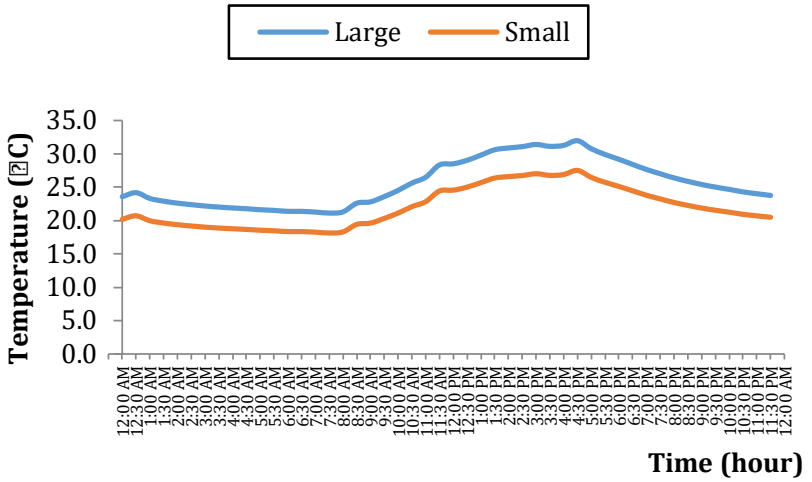

Figure 1. Root zone temperatures of large and small multi-tier structures vs time

Table 4. Model Summary

\begin{tabular}{lllll}
\hline Model Summary b & & & & \\
\hline Model & $\mathrm{R}(\mathrm{g})$ & R Square & Adjusted R Square & Std. Error of the Estimate \\
\hline 1 & 0.998 & 0.995 & 0.995 & 0.2511 \\
\hline
\end{tabular}

a Predictors: (Constant), WaterTemp, EnviTemp, SoilMC, SolarRad, WindSpeed

b Dependent Variable: RZT

Table 5. Coefficients

\begin{tabular}{|c|c|c|c|c|c|}
\hline \multicolumn{6}{|l|}{ Coefficients a } \\
\hline \multirow[t]{2}{*}{ Model } & \multicolumn{2}{|c|}{ Unstandardized Coefficients } & $\begin{array}{l}\text { Standardized } \\
\text { Coefficients }\end{array}$ & \multirow{2}{*}{$\mathrm{t}$} & \multirow{2}{*}{ Sig. } \\
\hline & B & Std. Error & Beta & & \\
\hline 1 (Constant) & -0.005 & 1.558 & & -0.003 & 0.997 \\
\hline WaterTemp & 0.596 & 0.041 & 0.566 & 14.475 & 0.000 \\
\hline EnviTemp & 0.327 & 0.07 & 0.343 & 4.699 & 0.000 \\
\hline SoilMC & 0.251 & 0.051 & 0.058 & 4.888 & 0.000 \\
\hline SolarRad & 0.005 & 0.001 & 0.197 & 3.928 & 0.000 \\
\hline WindSpeed & -0.891 & 0.363 & -0.031 & -2.451 & 0.018 \\
\hline
\end{tabular}

a Dependent Variable: RZT

\subsection{Conclusions}

From the experiment conducted, it was found that there was no significant difference between root zone temperature at different levels and lengths on multi-tier structure. However, when comparing the root zone temperature with a small scale structure, the large structure tends to have a higher root zone temperature. Consequently, the system's ability to provide a suitable environment for crop growth will be decreased. From the regression model, RZT $=-0.005+0.596$ (Water Temperature) + 0.327 (Environment Temperature) + 0.251 (Soil Moisture Content) +0.005 (Solar Radiation) -0.891 (Wind Speed), shows that several factors such as chilling pipe material selection, types of growing media used, types of crop protection structure design and the chiller capacity could be manipulated to improve the performance of root zone cooling system.

\section{Acknowledgement}

The researchers would like to thank the staff of Engineering Research Centre MARDI for their assistance.

\section{Funding}

This research was supported by Rancangan Malaysia ke 9 (RMK9) Development project under the Ministry of Agriculture and Food Industry Malaysia (MAFI).

\section{Author contributions}

Ahmad Syafik Suraidi Sulaiman - Conceptualization, Methodology, Data curation and Writing original draft preparation. Mohd Ashraf Zainol Abidin - Data curation and Writing- draft preparation. Desa Ahmad - Supervison, Writingreview and Editing

\section{Conflict of interests}

The authors declare no conflict of interest, and also the funders had no role in the design of the study; in the collection, analyses, or interpretation of data; in the writing of the manuscript, or in the decision to publish the results.

\section{References}

Abou-Hadid, A.F. and El-Behairy, U.A. 1999. Soilless culture, a tool for maximizing the utilization of arid land resources. Cahiers options Mediterranes 31:325-345.

Bartholomew, M. (2005). Square foot gardening: a new way to garden in less space with less work. Rodale Books

Derek, F. (2011). Vertical gardening: grow up, not out, for more vegetables and flowers in much less space. Rodale Books.

Gosselin, A., \& Trudel, M. J. (1984). Interactions between rootzone temperature and light levels on growth, 
development and photosynthesis of Lycopersicon esculentum Mill. cultivar "Vendor." Scientia Horticulturae, 23(4), 313-321. doi:10.1016/0304-4238(84)90027-X

Incropera, F.P., Dewitt, D.P., Bergman, T.L., \& Lavine, A.S. (2007). Fundamentals of heat and mass transfer. 6th Edition. John Wiley \& Sons (Asia) Pte Ltd.

Mat Sharif, I. (2006). Design and development of fully controlled environment greenhouse for the production of selected temperate crops in lowland tropics. In International Symposium on Greenhouse, Environmental Controls and In-house Mechanization for Crop Production in Tropics and Sub-tropics (pp. 127-134). Cameron Highlands: Acta Horticulturae (ISHS) 710.

Mohd Ashraf, Z.A., Ahmad, D., Ahmad Syafik, S.S., Hafiz, M.Y. and Noraznal, M.Z. (2013). A Preliminary study on the effects of chilled pipes in controlling the root zone temperature of a multi-tier cropping system. 2013 IEEE Symposium on Business, Engineering and Industrial Applications.
Mohd Ridzuan, M. S., Mohammad Abid, A., Saiful, Z. J., Roslina, A., Ahmad Tarmizi, S., Mahamud, S., ... Abdullah, W. Y. (2011). Manual of strawberry cultivation technology using fertigation system (1st ed.). Kuala Lumpur: Mardi Publication.

Wan Fazilah Binti Fazli Ilahi. Hysteresis of cocopeat-perlite mixture under root zone cooling system for growing butterhead lettuce. (2017). Thesis Submitted to the school of Graduate Studies, Universiti Putra Malaysia, in Fulfilment of the Requirements for the Degree of Doctor of Philosophy

Yahya, A., Anieza, S.S., Rosli, M., and Ahmad, S. (2009). Chemical and Physical Characteristics of cocopeat-based media mixtures and their effects on the growth and development of Celosia cristata. American Journal of Agricultural and Biological Sciences 4 (1): 63 - 71. 